\title{
VIGILÂNCIA EPIDEMIOLÓGICA E DIREITOS CONSTITUCIONAIS ${ }^{(*)}$
}

\author{
EPIDEMIOLOGICAL SURVEILLANCE AND CONSTITUCIONAL RIGTHS
}

Carlos Ari Sundfeld ${ }^{(*)}$

\section{RESUMO}

A Administração Pública possui o poder-dever de vigilância sanitárioepidemiológica, tendo como fim, no caso da dengue, a eliminação do mosquito transmissor da doença - o Aedes aegypti - e o combate às epidemias. Tal objetivo é perseguido com o ingresso de agentes sanitários em espaços privados, como residências e estabelecimentos comerciais. É neste momento que se instala o confronto entre autoridade e liberdade: há a possibilidade de resistências à entrada dos agentes, por parte de proprietários, além da existência de imóveis fechados e abandonados. Assim, em contraposição ao papel do Estado de cuidar da saúde (arts. 23, 24, 196 e ss. da $\mathrm{CF} / 88$ ) está a garantia constitucional da inviolabilidade do domicílio (art. $5^{\circ}$, $\mathrm{XI}, \mathrm{CF})$.

Dessa maneira, trazemos ao debate o confronto entre dois mandamentos constitucionais. Após a análise de cada um deles, a partir de julgados do Supremo Tribunal Federal, conclui-se pela sobreposição de um ao outro: o interesse público de cuidar da saúde e de combater epidemias se eleva diante da garantia da inviolabilidade de domicílio.

\section{Palavras-chave}

Vigilância sanitário-epidemiológica, Inviolabilidade de domicílio, Dengue.

(*) Este trabalho contém as conclusões pessoais do autor a partir dos resultados de pesquisa desenvolvida no Centro de Pesquisas Aplicadas da Sociedade Brasileira de Direito Público - SBDP pelo seguinte grupo: Prof. Carlos Ari Sundfeld (coordenador), Prof. Conrado Hübner Mendes (diretor de pesquisa), alunos da Escola de Formação da SBDP Amauri Feres Saad, Carolina Martins Marinho, Daniel G. Falcão Pimentel dos Reis, Diogo de Carvalho e Matheus Parducci Camargo (pesquisadores em iniciação científica), bem como a ex-aluna Denise Vasques. $O$ trabalho deriva de solicitação do Centro de Estudos e Pesquisas de Direito Sanitário - CEDISA.

(**) Professor Doutor da Faculdade de Direito e da Pós-graduação em Direito da Pontifícia Universidade Católica de São Paulo. Presidente da Sociedade Brasileira de Direito Público - SBDP. 


\section{ABSTRACT}

Public Administration has the power-duty of sanitary epidemic vigilance, aiming at, in the event of dengue, eliminating the mosquito that transmits the disease - Aedes aegypti - and combating epidemics. Such objective is pursued through the entrance of public sanitary agents in private places, such as residences and commercial establishments. It is at this point that the confront between authority and liberty is established: there is the possibility of resistance to the entrance of the agents, by the owner, besides the existence of closed and abandoned properties. Hence, opposing to the state role of looking after health (Federal Constitution, articles 23, 24, 196 and following) is the constitutional guarantee of domicile inviolability (Federal Constitution, article $5^{\circ}, \mathrm{XI}$ ).

Therefore, we raise the confront between two constitutional orders. After the analysis of each one, and based on decisions of the Brazilian Supreme Court, we conclude about the overpositioning of one over the other: health and combating epidemics public interest ascends before the guarantee of domicile inviolability.

\section{Keywords}

Sanitary epidemic vigilance, Domicile inviolability, Dengue.

\section{INTRODUÇÃO}

O objeto deste estudo - intervenção estatal no exercício da função de vigilância epidemiológica - insere-se em um dos capítulos mais apaixonantes do direito público: o das tensões entre a autoridade e a liberdade. Como se devem interpretar os mandamentos constitucionais de proteção da liberdade individual diante da exigência, igualmente constitucional, de proteção e defesa da saúde pública? Quais são a abrangência e os limites da atividade de ordenação da Administração Pública em matéria sanitária? É necessária legislação infraconstitucional específica para a realização do controle sanitário visando à redução do risco de contrair uma doença como a dengue hemorrágica?

O problema prático da vigilância epidemiológica para prevenção da dengue é o fato de sua eficácia depender do acesso dos agentes sanitários aos ambientes privados, como habitações e estabelecimentos, para descoberta e combate dos focos do Aedes aegypti.(1) Isso propõe duas questões

(1) Quanto aos desafios práticos envolvidos, valho-me de relato oriundo da Fundação Nacional de Saúde - Funasa e subscrito por Fabiano Geraldo Pimenta Jr., responsável pelo CENEPI: 
jurídicas muito concretas. É viável constitucionalmente o Estado impor às pessoas o dever de suportar o ingresso de agentes sanitários nos ambientes privados? Qual a reação estatal possível em caso de frustração desse ingresso, seja por resistência ou por ausência do morador?

A genérica atuação do Estado para promoção e defesa da saúde se dá no âmbito tanto de uma administração de serviços, por meio do fornecimento de prestações fruíveis individual ou coletivamente (serviços de saúde), quanto da administração ordenadora, que se manifesta pela imposição de deveres, positivos e negativos, condicionadores do exercício de direitos individuais, bem como pela fiscalização e sancionamento (vigilância sanitária e epidemiológica). É justamente nesse segundo campo, o da ordenação administrativa, que nosso estudo se insere.

Duas notas conceituais simples devem ser feitas a título de introdução, relativas, uma, ao fundamento da ordenação, e outra, ao seu limite.

O pressuposto lógico da existência da ordenação administrativa é a aceitação da sujeição dos indivíduos à autoridade pública. Mas o que justifica o poder de sujeitar? A essa resposta, que outrora se buscou na religião ou na metafísica, o Estado contemporâneo vinculou à idéia de função social. Na conhecida formulação de Duguit. "o poder de dominação persiste sempre; mas não é um direito subjetivo de que o Estado como pessoa jurídica seria titular: é, acima de tudo, uma função social". (2) Nessa linha, o

"A única forma de se evitar a ocorrência de epidemias de dengue consiste no combate ao vetor dessa doença, o mosquito Aedes aegypti. Juntamente com a efetiva participação da população, o combate ao Aedes aegypti depende, fundamentalmente, das ações empreendidas pelo poder público, destacando-se entre elas as seguintes: visita domiciliar em todos os imóveis dos municípios, realizada pelo agente de saúde pública, objetivando a eliminação dos potenciais criadouros do mosquito; educação em saúde buscando a adoção de medidas individuais que previnam a existência do Aedes nas residências e a aplicação de larvicidas em recipientes que acumulam água e não são passiveis de eliminação; abastecimento de água com regularidade; coleta e destino adequado do lixo doméstico.

Quando o mosquito está disperso em várias regiōes (bairros) de um determinado município, é imprescindivel que todos os imóveis deste município (residências, comércios, prédios públicos, terrenos baldios) sejam trabalhados pelos agentes de saúde com uma periodicidade máxima de 60 dias. Um dos obstáculos para que essa atividade alcance o resultado esperado, ou seja, a redução da população de Aedes aegypti a niveis inferiores a 1\%, o que evita a ocorrência de epidemias de dengue, são os imóveis que estão fechados no momento da visita do agente e aqueles em que 0 proprietário não permite que se realize o seu trabalho (recusas).

Em municípios com infestação domiciliar significativa (normalmente maior do que 5\%) e em estações do ano favoráveis ao desenvolvimento do vetor, com elevadas temperaturas e chuvas regulares, um índice de pendência (casas fechadas e recusas) em torno de $20 \%$, que é a realidade de Estados como Minas Gerais e Rio de Janeiro, pode ser suficiente para manter a transmissão de dengue, mesmo que o trabalho seja realizado satisfatoriamente nos demais imóveis.

Para melhor ilustrar essa situação exemplificamos com o caso do município do Rio de Janeiro, que tem aproximadamente 2.754 .000 imóveis a serem visitados a cada dois meses e um indice de pendência médio de $20 \%$. Isso significa que cerca de $\mathbf{5 5 0 . 0 0 0 ~ n a ̃ o ~ s a ̃ o ~ t r a b a l h a d o s ~ a ~ c a d a ~ d o i s ~}$ meses, o que propicia condições para transmissão da dengue, principalmente no verão".

(2) Las tranformaciones del derecho público. Tradução espanhola de Adolfo Posada e Ramón Jaen. $2^{3}$ ed., Madrid, 1913, p. 92. 
que fundamenta a sujeição individual é o proveito coletivo (o interesse público). Mas essa capacidade dominadora do geral sobre o particular é circunscrita pelo fato de os indivíduos desfrutarem de espaços individuais de ação, intangíveis pelo Estado (as liberdades, no sentido moderno). Assim, a sujeição individual pode ser imposta desde que respeitado o limite da liberdade individual.

Essas duas questões - a definição do interesse público, que justifica a atuação estatal, e a garantia da liberdade individual, que a limita - são, no Estado constitucional, eminentemente jurídicas. Perante qualquer intervenção administrativa ordenadora é preciso, então, indagar se há um interesse público, normativamente definido, que a justifique, e se ela respeita o conteúdo necessário dos direitos individuais.

É esse o teste para aferição da legitimidade do ingresso, nos ambientes privados, dos agentes sanitários incumbidos do combate à dengue.

Para aplicá-lo, é preciso desde logo atentar para dois possíveis sentidos da expressão "interesse público", a justificar um desdobramento conceitual: interesse público em sentido mínimo e interesse público em sentido forte. Quando o Direito atribui ao Estado o dever de cuidar de certo valor, está implicitamente definindo-o como interesse público, que legitima a atuação estatal (interesse público em sentido mínimo). Só que isso não importa necessariamente em tomada de posição da ordem jurídica quanto à prevalência desse valor sobre outros, que com ele se choquem, pois algo pode ser sério o bastante para ensejar a atuação do Estado, mas não sê-lo a ponto de justificar o sacrifício de outros bens. Quando o Direito consagra essa prevalência, pode-se falar em interesse público em sentido forte. Essa expressão serve para descrever a relação entre dois valores, um que prevalece (o interesse público em sentido forte) e o que cede (o interesse simples).

Vejamos, então, como esses conceitos incidem no campo da saúde pública.

\section{AS BASES NORMATIVAS DA VIGILÂNCIA EPIDEMIOLÓGICA}

Foi a própria Constituição brasileira de 1988 que qualificou a proteção e defesa da saúde como interesse público a ser perseguido pelo Estado. A ele incumbe cuidar da saúde (art. 23, II - competência comum da União, Estados, Distrito Federal e Municípios) ou fazer a proteção e defesa da saúde (art. 24, XII - competência legislativa concorrente da União e Estados). Segundo a Constituição, isso envolve, entre outras, a atribuição de executar ações de vigilância sanitária e epidemiológica (art. 200, 11 - competências do Sistema Único de Saúde). 
E o que se entende por vigilância epidemiológica? A resposta não está, claro, na Constituição, mas na Lei Orgânica da Saúde (Lei Federal n. 8.080, de 19 de setembro de 1990, editada pelo Congresso Nacional com base na competência legislativa do art. 24 , XII, da CF), que assim a define: "entendese por vigilância epidemiológica um conjunto de ações que proporcionam o conhecimento, a detecção ou prevenção de qualquer mudança nos fatores determinantes e condicionantes de saúde individual ou coletiva, com a finalidade de recomendar e adotar as medidas de prevenção e controle das doenças e agravos" (art. 6ㅇ, $\S 2^{\circ}$ ).

As ações de vigilância epidemiológica estão reguladas pela Lei Federal n. 6.259 , de 30 de outubro de 1975, segundo a qual compete à autoridade sanitária: a) "proceder à investigação epidemiológica pertinente para ... averiguação da disseminação da doença na população sob o risco" (art. 11, caput); b) "exigir e executar investigações, inquéritos e levantamentos epidemiológicos junto a indivíduos e a grupos populacionais determinados, sempre que julgar oportuno, visando à proteção da saúde pública" (art. 11, parágrafo único); e c) "adotar, prontamente, as medidas indicadas para o controle da doença, no que concerne a indivíduos, grupos populacionais e ambiente" (art. 12).

A Lei n. 6.259/75 foi expressa ao impor o dever de atender às imposições da autoridade sanitária destinadas ao controle de doenças transmissíveis. De acordo com o art. 13 da Lei, "as pessoas físicas e as entidades públicas ou privadas, abrangidas pelas medidas referidas no art. 12 , ficam sujeitas ao controle determinado pela autoridade sanitária". A inobservância desse dever ficou submetida às conseqüências previstas na Lei sobre infrações à legislação de saúde. ${ }^{(3)}$ De acordo com o art. 10 da Lei n. 6.437/77, constituem infrações sanitárias, entre outras, "impedir ou dificultar a aplicação de medidas sanitárias relativas às doenças transmissíveis ..." (VII), "obstar ou dificultar a ação fiscalizadora das autoridades sanitárias competentes no exercício de suas funções" (X), bem como a "inobservância das exigências sanitárias relativas a imóveis, pelos seus proprietários, ou por quem detenha legalmente a sua posse" (XXIV).

Esse conjunto normativo, de nível constitucional e legal, parece à primeira vista capaz de suportar juridicamente medidas interventivas, como o ingresso de agentes sanitários nos ambientes privados. $O$ "controle de doenças" é, segundo a Constituição, uma missão pública. Para viabilizar seu cumprimento, as leis conferiram às autoridades sanitárias competência para adotar as medidas indicadas para o controle da doença, no que concerne a in-

(3) À época, esse papel era cumprido pelo Decreto-lei n. 785, de 25 de agosto de 1969. Atualmente, o diploma aplicável é a Lei Federal n. 6.437, de 20 de agosto de 1977, que está em vigor com as alterações introduzidas pelo art. 12 da Medida Provisória n. 2.190-34, de 23 de agosto de 2001. 
divíduos, grupos populacionais e ambiente", ficando as pessoas "sujeitas ao controle determinado" (Lei n. 6.259/75, arts. 12 e 13). Não há dúvida que o controle de doenças configura interesse público ao menos em sentido mínimo, já que a atuação estatal foi autorizada. Mas as normas foram além, pois conferiram ao Estado o poder de sujeitar as pessoas em nome do controle de doenças. Em princípio, estão presentes elementos para reconhecer a presença de interesse público em sentido forte.

A Lei não contém um rol exaustivo das medidas inseridas na autorização, ${ }^{(4)}$ mas é clara ao definir seu escopo (o controle de doenças) e seu âmbito de incidência (os indivíduos, os grupos e o ambiente). A indicação das exatas medidas a adotar foi, pela lei, transformada em questão técnica, a ser resolvida a partir de juizos de discricionariedade técnica. ${ }^{(5)}$ Pela lógica normativa, para legitimar o ingresso compulsório em ambientes privados basta a demonstração de que se trata de medida indispensável ao controle dos vetores transmissores das moléstias infecciosas. ${ }^{(6)}$ Segundo os especialis-

(4) A Lei cita e regula com certo detalhe duas medidas: a vacinação (dentro do programa nacional de imunizações - arts. $3^{2}$ a $6^{\circ}$ ) e a notificação compulsória de doenças (arts. $7^{\circ}$ a 10 ), mas seu espectro é mais amplo, como se vê do citado art. 12 e de outros preceitos. São exemplos o art. $1^{2}$, caput, que atribui ao Ministério da Saúde a coordenação das "ações relacionadas com o controle das doenças transmissíveis, orientando sua execução inclusive quanto à vigilância epidemiológica, à aplicação da notificação compulsória, ao programa de imunizações e ao atendimento de agravos coletivos à saúde, bem como os decorrentes de calamidade pública", assim como 0 art. $2^{2}$, caput, de acordo com o qual "a ação de vigilância epidemiológica compreende as informações, investigações e levantamentos necessários à programação e à avaliação das medidas de controle de doenças e de situações de agravo à saúde".

(5) Essa técnica legislativa - consistente em enunciar os objetivos, sem fixar taxativamente o elenco de possíveis intervenções sanitárias - tem larga tradição entre nós, tendo sido usada no Decreto n. 68, de 18 de dezembro de 1889, editado logo após a República para tratar do "serviço de policia sanitária e adota( $r$ medidas para impedir ou atenuar o desenvolvimento de quaisquer epidemias". Seu art. $1^{2}$ dispós genericamente que "o inspetor geral de higiene tem liberdade de ação imediata, com iniciativa de execução, em todos os assuntos de saúde pública, urgentes ou regulamentados, competindo-Ihe intervir direta ou indiretamente na fiscalização de todos os serviços sanitários de terra". De outra parte, o decreto instituiu, como medidas específicas, a notificação compulsória, a desinfecção obrigatória e o isolamento nosocomial (art. $3^{2}$ ), bem como a vacinação obrigatória contra a variola (art. $5^{2}$ ). Pouco depois, no Regulamento do Serviço Sanitário baixado com o Decreto n. 169, de 18 de janeiro de 1890, atribuiu-se à inspetoria geral de higiene "a adoção dos meios tendentes a prevenir, combater ou atenuar as molésticas endêmicas, epidêmicas e transmissiveis ao homem e aos animais" (art. 9, III).

(6) Registre-se que, embora a lei vigente não mencione expressamente a visita domiciliar, a pertinência dessa medida no contexto do controle das epidemias é historicamente admitida pelas normas sanitárias. Cite-se, como exemplo remoto, o Decreto n. 4.464, de 12 de julho de 1902, que estabeleceu "as bases para a regulamentação dos serviços de higiene de defesa na Capital Federal", cujo art. $1^{2}$ assim dispôs: "a) A polícia sanitária federal terá por objeto a averiguação dos casos de moléstias transmissíveis e o emprego dos meios adequados à extinção das epidemias e endemias, excetuados os referentes à higiene de agressão. O conhecimento dos casos ocorrentes de tais moléstias resultará da indagação e da notificação compulsória. A indagação consistirá nas visitas domiciliarias em zona ou região em que aparecem casos de moléstias transmissiveis ou haja receio que apareçam. Nessas visitas a autoridade federal terá qualidade para apreciar as condições do meio em que se manifestarem as referidas moléstias e para indicar a precisa correção, quer aplicando as leis federais ou municipais, quer solicitando a quem de direito as providências extraordinárias (...)". 
tas, é esse o caso da dengue, transmitida pelo mosquito Aedes aegypti, que prolifera em recipientes como pneus, garrafas, vasos de plantas, calhas e piscinas existentes nos ambientes privados.

Está cumprida, assim, a primeira parte do teste para aferição da legitimidade da medida, pois ela atende a um interesse público definido normativamente, na Constituição Federal e em leis no sentido formal: o de impedir a propagação das epidemias. Resta, porém, a segunda parte do teste: a medida atinge de modo impróprio direito individual?

\section{O CONFRONTO ENTRE A LIBERDADE INDIVIDUAL E AS MEDIDAS SANITÁRIAS}

A instituição e proteção de um espaço de liberdade para cada indivíduo é um dos objetivos fundantes do constitucionalismo.

Duas estratégias foram adotadas pela Constituição para impiementar esse programa. De um lado, consagrou-se uma lista de direitos individuais necessários, que não podem ser negados pela lei (direitos à vida, à liberdade de locomoção, de manifestação do pensamento). De outro, instituiram-se mecanismos de ordem formal para controle das constrições incidentes sobre os indivíduos: a reserva legal e a autorização judicial. Pela reserva legal, certas constrições sensive is ficaram dependentes de previsão legal específica (o exemplo inevitável é o do art. 5, XXXIX: "não há crime sem lei anterior que o defina, nem pena sem prévia cominação legal"). Algumas constrições não podem ser impostas por ato administrativo, dependendo de autorização judicial prévia, como nos casos da prisão (art. 5o, LXI), da expropriação (art. $5^{\circ}, \mathrm{XXIV}$ ) e da dissolução de entidade (art. $5^{\circ}, \mathrm{XIX}$ ).

As ações estatais no campo da saúde, conquanto atendam a objetivos públicos assumidos pela ordem jurídica vigente, com freqüência são onerosas ou incômodas para os indivíduos, obrigados a agir (a notificar a ocorrência de doenças, p. ex.), a abster-se (não usar substâncias tóxicas) e a suportar interferências estatais (como a vacinação). Daí o debate sobre a legitimidade das medidas constritivas, pelo ângulo do respeito à liberdade individual. A aferição envolve a pesquisa de três aspectos: a carga ablativa da medida atinge o conteúdo mínimo de algum direito individual? Há reserva legal? É constitucionalmente viável a aplicação da medida por ato administrativo, sem autorização judicial?

A primeira questão, relativa ao conteúdo mínimo de certo direito, envolve sempre discussões constitucionais delicadas. O Supremo Tribunal Federal as vem enfrentando ao longo do tempo. Direitos individuais freqüentemente invocados contra medidas sanitárias, como os da intimidade (art. 50, 
$\mathrm{X}$ ), propriedade (art. 5, XXII) e inviolabilidade do domicílio (art. $5^{\circ}, \mathrm{XI}$ ), têm sido objeto de debate na Corte.

Recentemente, o STF entendeu como violadora do direito à intimidade a submissão forçada de alguém a um exame laboratorial para o fim de determinar a paternidade (interesse entendido como privado), mas, na fundamentação do acórdão, ressalvou a viabilidade de outras constrições físicas determinadas pelo interesse público (como na hipótese da vacinação obrigatória). ${ }^{(7)}$ Seguindo a lógica do raciocínio, a validade de uma medida sanitária é determinada pela importância do interesse que tutela, não pelo tipo ou grau de constrição que produz sobre o indivíduo. ${ }^{(8)}$ Assim, o direito à intimidade não conferiria imunidade sequer diante de constrições físicas, pois estas, apesar de invasivas, seriam possíveis quando amparadas por uma causa legítima.

Mas como aferir a existência de causa legítima para o condicionamento de um direito previsto constitucionalmente? A retórica da Corte usa recorrentemente duas expressões: "interesse público" e "poder de polícia". Sinteticamente, as idéias são as seguintes: a) em nome do interesse público é viável à lei ou à Administração estabelecer condicionamentos a direitos individuais, ainda que conferidos pela Constituição; b) o Estado dispõe de um poder de polícia para conformar o exercício dos direitos individuais ao interesse público.

(7) Trata-se do HC 71373-4-RS (Tribunal Pleno, rel. Marco Aurélio, j. 10.11.1994, maioria), impetrado pelo réu em ação de investigação de paternidade contra sua condução ao laboratório, debaixo de vara, para coleta de sangue destinado a exame de DNA. O relator sorteado, Francisco Rezek, votou contra o pedido, afirmando: “... o direito ao próprio corpo não é absoluto ou ilimitado. Por vezes a incolumidade corporal deve ceder espaço a um interesse preponderante, como no caso da vacinação, em nome da saúde pública. ... Estou em que o princípio da intangibilidade do corpo humano, que protege um interesse privado, deve dar lugar ao direito à identidade, que salvaguarda, em última análise, um interesse também público". Ilmar Galvão aderiu, nestes termos: "Tratase de interesse que ultrapassa os limites estritos da patrimonialidade, possuindo nítida conotação de ordem pública, aspecto suficiente para suplantar, em favor do pretenso filho, o egoístico direito à recusa, fundado na incolumidade física, no caso, afetada em proporção ridículan. Votaram no mesmo sentido Carlos Velloso e Sepúlveda Pertence. Marco Aurélio, no voto condutor da maioria, rechaçou esse ponto de vista: “É irrecusável o direito do paciente de não permitir que se Ihe retire, das próprias veias, porção de sangue, por menor que seja, para a realização do exame. ... Assim o é porque a hipótese não é daquelas em que o interesse público sobrepõe-se ao individual, como a das vacinações obrigatórias em época de epidemias, ou mesmo a busca da preservação da vida humana, naqueles conhecidos casos em que convicções religiosas arraigadas acabam por conduzir à perda da racionalidade". Em voto também vencedor, Octávio Gallotti disse, referindo-se ao direito à determinação da paternidade: "E é um direito individual, não corresponde a um interesse coletivo, como sucederia se se tratasse de um processo criminal, ou também na hipótese, aqui aventada, da vacinação, que responde à proteção de um interesse de saúde pública". Compuseram a maioria, ainda, Celso de Mello, Sydney Sanches, Neri da Silveira e Moreira Alves.

(8) Em princípio, serão inviáveis apenas as constrições que se choquem com o direito à vida, embora mesmo ai haja exceção: a prevista no art. 128 do Código Penal, que, em certas gestações de alto risco, autoriza o sacrifício da vida do filho para salvar a da mãe. 
Aplicando essa formulação aos casos concretos, o STF avalia se o interesse por trás do condicionamento é relevante a ponto de merecer o rótulo de interesse público em sentido forte. Trata-se de uma ponderação de interesses, destinada a verificar, por um lado, a importância social da finalidade objetivada e, de outro, a necessidade, adequação e proporcionalidade da medida. ${ }^{(9)}$

Assim, p. ex., a liberdade de profissão pode ser limitada pela necessidade de vigilância sanitária dos bens comercializados; ${ }^{(10)}$ a liberdade de ir e vir pode ser limitada pela necessidade de isolamento hospitalar em caso de doença transmissível;(11) o direito de propriedade pode ser limitado pela necessidade de observar as exigências administrativas de desinfecção e reparo do imóvel, fundadas na higiene pública; ${ }^{(12)} 0$ direito de posse sobre

(9) Nos últimos anos, a Corte vem recorrendo à noção de razoabilidade para fazer a apuração quanto à existência de uma causa legítima para a interferência estatal, como relata o Min. Celso de Mello, em despacho como Presidente: "A jurisprudencia constitucional do Supremo Tribunal Federal, bem por isso, tem censurado a validade jurídica de atos estatais, que, desconsiderando as limitaçōes que incidem sobre o poder normativo do Estado, veiculam prescriçōes que ofendem os padrōes de razoabilidad: e que se revelam destituidas de causa legítima, exteriorizando abusos inaceitáveis e institucion lizando agravos inúteis e nocivos aos direitos das pessoas (RTJ 160/140, rel. Min. Celso de Mello; ADIn 1063-DF, rel. Min. Celso de Mello, v.g.)" (Despacho na Suspensão de Segurança 1.320-9, União Federal x TRF da $1^{2}$ Região, 6.4.1999).

Como exemplo interessante de polêmica quanto ao exercício da autoridade administrativa em matéria sanitária, mencione-se caso julgado pela 1 ' Câmara da Corte de Apelação do Rio de Janeiro em 1.10.1908 (Apelação crime n. 509, Apelante Antônio Gonçalves Possas, Apelada Justiça Sanitária, em O Direito, set./dez. de 1908, vol. 107, p. 322), relativo à condenação criminal decorrente do desatendimento de intimação da autoridade sanitária para reforma em prédio, incluindo-se determinação para mudança da natureza do uso da edificação. Em seu voto vencido, contrário à manutenção da condenação, o juiz Montenegro argumentou no sentido da inadequação da exigência administrativa, in verbis: "As atribuiçōes, pois, que aos funcionários da higiene cometem o Decreto Legislativo n. 1.151, de 1904, e respectivo regulamento expedido para a sua execução, no intuito da 'vigilância e polícia sanitária' repelem o arbitrio na indicação de obras que não forem necessárias e restritamente reclamadas no interesse da 'salubridade pública' (...). A intimação por cópia a fls. 3, para a execução de obras que 'transformassem todo o pavimento térreo do prédio n. 215 da rua de S. Pedro, atualmente constituído domicílio de familia' em 'armazém para fins comerciais', é uma ordem ilegal, ato de violência, que arbitrariamente transmuda o domínio, deixando, portanto, de ser obrigatória para o intimado. (....)".

(10) STF, Apelação cível 1.252, Distrito Federal x Pedro Rodrigues França Leite, j. 6.5.1908 (em O Direito, Rio de Janeiro, 1908, vol. 106, p. 400). Discutia-se a proibição de comercializar carne de gado que não tivesse sido examinado em pé pelas autoridades sanitárias, proibição essa contestada como violadora do direito ao exercício profissional. Entendeu a Corte: “... a regulamentação do fornecimento de alimentação à população ... pertence exclusivamente à polícia do Estado, e são lícitas as restrições postas à liberdade de profissão, desde que se trata de serviços que devem ser executados ou fiscalizados pelo Estado".

(11) STF, HC 2.642, paciente Roberto Francisco Bernardes, j. 9.12.1908 (em O Direito, Rio de Janeiro, 1908, vol. 107, p. 609). Disse o Tribunal: "Não constitui constrangimento ilegal contra Roberto Francisco Bernardes o fato de ter este, afetado de peste bubônica, sido removido para o hospital de São Sebastião, mormente quando a respeito foram observadas as prescrições da lei da higiene administrativan.

(12) A jurisprudência nesse sentido foi firmada pelo STF a partir dos Acórdãos 363 , de 22 de agosto de 1900, e 372, de 13 de outubro de 1900, acolhendo o entendimento de que "o ato da autoridade sanitária praticado no alto interesse da saúde pública não constitui ameaça de turbação de posse" (a referência a esses julgados está no Agravo n. 501, comendador Anselmo José Barbeito x Juízo 
hortas e capinzais pode ser limitado pela necessidade de destruí-los, em benefício da saúde pública;(13) a liberdade de culto pode ser limitada pela necessidade de respeitar a precedência de outra igreja no uso de ritos e vestes tradicionais; ${ }^{(14)}$ a liberdade de ir e vir pode ser limitada pela neces-

Federal, j. 1.8.1903, em O Direito, Rio de Janeiro, 1904, vol. 93, p. 41). Várias decisões posteriores confirmaram essa jurisprudência, valendo menção os seguintes: a) STF, Agravo cível, Arthur Paulo de Souza x Juizo Federal da 2' Vara, j. 8.4.1905 (em O Direito, Rio de Janeiro, vol. 98, p. 88), questionando intimação da autoridade sanitária para fazer obras em prédio, que seria violadora do direito de propriedade; pedido negado pelo Tribunal pois "evidentemente não se atenta contra a posse do agravante com as exigências da saúde pública constantes da notificação de fls. 4, compreendendo a limpeza do prédio, que aliás permanece em toda sua integridade"; b) STF, Agravo civel n. 1.211, Antonio José da Fonseca Moreira x União Federal, j. 1.12.1909 (em O Direito, Rio de Janeiro, 1911, vol. 115, p. 553), acórdão em que se manteve decisão denegatória de mandado de manutenção de posse requerido contra a Diretoria Geral de Saúde Pública para afastar "o ingresso da autoridade sanitária (em prédio particular) a fim de desinfectá-lo e determinar a limpeza e os reparos necessários, de acordo com o regulamento sanitário em vigor", uma vez que "as medidas administrativas emanadas daquela diretoria não constituem turbação de posse, pois foram unicamente expedidas em virtude de atribuições legais, reclamadas pela higiene públican; c) STF, Agravo 1170, Casimiro Pereira Cotta x A Saúde Pública, j. 28.8.1909 (em O Direito, Rio de Janeiro, 1909 , vol. 110, p. 264), no qual se decidiu que "a autoridade sanitária administrativa é competente para interditar prédios; contra os atos dessa autoridade não podem ser expedidos mandados proibitórios".

Essa doutrina não deixou, contudo, de suscitar polêmica, valendo citar parecer de Lafayette Rodrigues Pereira: “A Diretoria da Saúde não pode obrigar os proprietários a fazerem obras nos seus edifícios, a reconstrui-los, a alterar-lhes o plano. Tais atos são dominicais, isto é, de senhor e possuidor; e praticá-tos a autoridade pública importa tanto como intervir no governo e administração do património particular e destarte infringir o citado $\S 17$ do art. 72 da Constituição. Um semeIhante procedimento só seria possivel no regime do Estado Socialista, segundo o qual os individuos são considerados pupilos, sob a tutela do poder público, ao qual é entregue o governo e a administração da propriedade particular. A Constituição da República não ousou consagrá-lo" (em O Direito, mai/ago de 1905, vol. 97, p. 86).

(13) STF, Agravo 360, Ferreira da Silva e C. e outros $x$ União Federal, j. 4.8.1900, em O Direito, R. Janeiro, jan/abr 1901, vol. 84, p. 90. Tratava-se de agravo contra o indeferimento de mandado de manutenção de posse, pretendido para afastar a turbação causada por ato do diretor geral de saúde pública, que mandara destruir hortas e capinzais do interessado. No mérito, o Tribunal entendeu que "careciam de razão jurídica a violência e turbação de que se queixam os agravantes, porquanto: - Considerando que as medidas tomadas pela autoridade competente, de acordo com uma lei preexistente, o decreto municipal supracitado, em benefício da saúde pública, de modo algum deve ser considerado violência a nenhum direito de posse, que tenda a autorizar a ação de força nova turbativa; - Considerando que, se aos indivíduos fosse permitido, em tempo de peste ou guerra, semelhante remédio possessório, estaria ipso facto entorpecida a ação da autoridade, incumbida de velar pelo bem público; e assim - Considerando que em tais casos, aos prejudicados só é lícito pedir indenização do dano em sua propriedade, nos casos e nos termos permitidos na lei; - Assim julgando, confirmam o despacho agravado (...)".

(14) STF, MS 1.114, Igreja Católica Apostólica Brasileira x Presidente da República, j. 17.11.1949, rel. Hahnemann Guimarães, maioria (um voto vencido). Discutiu-se se a Igreja originada de um cisma da Igreja Católica Apostólica Romana podia ser impedida de funcionar, para evitar a confusão e o conflito entre ambas. O STF entendeu que sim. Dos votos vencedores dos Min. Ribeiro da Costa e Edgard Costa se pode colher a síntese do argumento que seduziu a maoria: Disse o primeiro: “... a questão toma aspecto simples, a ser estudado exclusivamente sob o ponto de vista do exercício do poder de polícia. Compete à autoridade policial tomar providéncias para impedir que adeptos de um culto venham a perturbar a ordem pública, pretendendo usar as insígnias, as práticas, os ritos, as vestes de outro culto, secularmente praticado e universalmente reconhecido". Completou o segundo: "A liberdade de consciéncia e de crença, essa é, por dispositivo expresso da 
sidade de proteger a moral e os bons costumes; ${ }^{(15)}$ o direito individual à preservação das tradições culturais pode ser limitado pela necessidade de proteger os animais contra a crueldade. ${ }^{(16)}$ Em todos esses exemplos, a presença de valores reconhecidos pela Corte como interesses públicos em sentido forte permitiu a compressão do conteúdo potencial de direitos assegurados na Constituição.

No tocante à ação da vigilância epidemiológica no combate à dengue, a questão conflituosa é a do acesso das autoridades sanitárias aos ambientes privados. O teste para aferição de sua legitimidade deve, portanto, ser aplicado considerando o direito à inviolabilidade do domicílio. ${ }^{(17)}$

Constituição, inviolável e irrestrita. A liberdade do exercício do culto não é, porém, absoluta. É relativa. Subordina-se aos interesses da ordem pública, aos interesses dos bons costumes e vai até onde não interfira com a liberdade conferida ou atribuída a terceiros".

(15) STF, Recurso no HC 59.518, Pleno, Francinete Soares de Castro x Tribunal de Justiça do Estado de São Paulo, j. 26.8.1982, rel. Cordeiro Guerra, maioria (2 votos vencidos). Debateu-se a concessão de habeas corpus em favor de prostituta para garantir seu direito de fazer o trottoir sem ser molestada pela autoridade pública. $O$ Tribunal negou a medida. O fundamento está resumido na confirmação de voto do relator: “... não contesto o direito de ir e vir da paciente. $O$ que eu sustento é que não pode exercê-lo em detrimento da moral e dos bons costumes. Acho que a Constituição da República dá os parâmetros fundamentais para assegurar as normas de bem viver. E não vejo, no poder de polícia, exercitado com moderação e equilíbrio, no interesse da moralidade e dos bons costumes, nenhum constrangimento à liberdade dos cidadãos brasileiros".

(16) STF, RE 153.531, 2a T., APANDE x Estado de Santa Catarina, j. 3.6.1997, rel. Marco Aurélio (um voto vencido). Estava em questão a proibição da prática da farra do boi, que o STF considerou necessária, pois "não há aqui uma manifestação cultural com abusos avulsos; há uma prática violenta e cruel para com animais, e a Constituição não deseja isso" (voto vencedor do Min. Francisco Rezek).

(17) Interessante observar que, abstraindo-se o problema da inviolabilidade do domicilio, a legitimidade das medidas sanitárias também pode ser discutida pela ótica da relação entre o próprio direito de propriedade e a reserva de jurisdição, se o atendimento dos interesses da saúde pública exigir uma intervenção mais radical no próprio bem, para destruí-lo ou modificá-lo. Quando, na vigência da Constituição de 1891, empreendeu-se larga campanha sanitária, uma concepção referente à propriedade fez com que a legislação limitasse o efeito das ordens administrativas sanitárias, cujo cumprimento envolvesse "despejo, demolição, interdição, desapropriação, obras de prédio ou qualquer propriedade", bem como a "cobrança de multas $\theta$ taxas sanitárias". Para todos esses casos, a "efetividade dos mandados e ordens das autoridades sanitárias" dependia da propositura de "ações e processos civis e criminais em matéria de higiene e salubridade pública", cujo conhecimento cabia ao "Juízo dos Feitos da Saúde Pública", conforme os arts. 279 a 292 do Regulamento dos serviços sanitários a cargo da União, editado pelo Decreto n. 5.156, de 8 de março de 1904, bem como o Regulamento processual da Justiça Sanitária editado pelo Decreto n. 5.224 , de 30 de maio de 1904. Assim, instituiu-se uma reserva jurisdicional para a execução das medidas de intervenção na propriedade. Aplicando essa solução, o STF, no Agravo n. 841, j. 13.10.1906 (em $O$ Direito, jan./abr. 1907, vol. 102, p. 304), manteve despacho do Juiz da $2^{2}$ Vara Federal, segundo o qual "(...) As esferas de ação das duas autoridades - a administrativa e a judiciária - estão neste ponto perfeita e nitidamente demarcadas. À primeira compete, nem podia deixar de competir, interditar os prédios e indicar os reparos, notificações e obras que o seu critério científico reputa indispensáveis, de acordo com os interesses da saúde pública, para que os mesmos prédios se tornem habitáveis. À segunda incumbe a execução destas medidas mediante fórmulas que se destinam principalmente a garantir a propriedade particular contra possiveis arbítrios. O mandado de fls. 12 não desconhece a competência da autoridade administrativa: tão somente veda que ela exorbite e invada as atribuições da autoridade judiciária, executando por suas próprias mãos as notificações que expediu ao autor". 


\section{A INVIOLABILIDADE DO DOMICÍLIO}

A Constituição de 1988 prevê, entre os direitos individuais, o da inviolabilidade do domicílio, nos seguintes termos: "a casa é o asilo inviolável do indivíduo, ninguém nela podendo penetrar sem consentimento do morador, salvo em caso de flagrante delito ou desastre, ou para prestar socorro, ou, durante o dia, por determinação judicial' (art. $5^{2}, \mathrm{XI}$ ). Esse direito tinha uma configuração tanto distinta na Carta de 1969, como segue: "a casa é o asilo inviolável do indivíduo; ninguém pode penetrar nela, à noite, sem consentimento do morador, a não ser em caso de crime ou desastre, nem durante o dia, fora dos casos e na forma que a lei estabelecer" (art. 153, § 10).

A casa, que é objeto da proteção constitucional, foi definida pelo art. 150 do Código Penal ao tipificar o crime de violação do domicílio. ${ }^{(18)} \mathrm{De}$ acordo com a Lei penal, por casa se entendem tanto os compartimentos habitados (inclusive os de habitação coletiva), como os destinados ao exercício de profissão ou atividade, desde que não abertos ao público $\left(\S 4^{2}\right)$. Não são casa os estabelecimentos abertos, como as tavernas e casas de jogo, e também hospedarias, estalagens e outras habitações coletivas, salvo quanto aos aposentos ocupados $\left(5^{\circ}\right)$.

Aparentemente, a Constituição atual tornou mais rígido o direito à inviolabilidade da casa.(19) $\mathrm{Na}$ ordem pretérita, a Lei poderia prever outros casos de ingresso forçado em domicílio alheio, estabelecendo a respectiva forma; não havia impedimento constitucional a que, se a Lei o autorizasse, a medida fosse tomada por decisão administrativa auto-executória. Na Carta vigente, porém, esse ingresso depende de determinação judicial.

A previsão, constante da antiga ordem constitucional, de que a Lei poderia prever casos de ingresso no domicílio, disciplinando a respectiva forma, ensejava debate quanto à existência ou não de uma reserva legal. $O$ tema foi analisado no STF pela primeira vez em 1905, quando decidiu ser

(18) O Código fol editado pelo Decreto-lei n. 2.848, de 7 de dezembro de 1940, à época da Carta de 1937, que tratava do assunto em seu art. 122, 6, limitando-se a assegurar o direito "à inviolabilidade do domicilio..., salvo as exceçōes previstas em lei". A atualidade, diante da ordem constitucional de 1988, do conceito de casa cunhado pela Lei penal foi afirmada recentemente em despacho do Presidente do STF: "Impõe-se destacar, por necessário, que o conceito de casa, para os fins da proteção jurídico-constitucional a que se refere o art. $5^{2}, \mathrm{XI}$, da Lei Fundamental, reveste-se de caráter amplo, pois compreende, na abrangência de sua designação tutelar, (a) qualquer compartimento habitado, (b) qualquer aposento ocupado de habitação coletiva e (c) qualquer compartimento privado onde alguém exerce profissão ou atividade. Esse amplo sentido conceitual da noção jurídica de casa revela-se plenamente consentâneo com a exigéncia constitucional de proteção à esfera individual e de liberdade pessoal (RT 214/409; RT 277/576; RT 467/385; RT 635/341)" (Despacho do Min. Celso de Mello - Presidente, na Suspensão de Segurança n. 1203, Distrito Federal X TJDF, j. 8.9.1997, em RDA vol. 210, p. 270).

(19) Sobre o tema, consultar amplamente Dinorá Adelaide Musetti GROTTI, Inviolabilidade do domicilio na Constituição. São Paulo: Malheiros, 1993, pp. 87 e ss. 
inconstitucional o tratamento da matéria por simples regulamento administrativo, ainda que autorizado por lei. ${ }^{(20)}$ Depois, e durante trinta anos, a partir de 1925, invocando a proteção constitucional da inviolabilidade do domicílio, entendeu pacificamente que o morador locatário não poderia ser constrangido a, no interesse do proprietário, permitir a visita do imóvel por pretendentes à aquisição, pois não havia lei que o impusesse. ${ }^{(21)}$ Em 1955, po-

(20) STF, HC 2.244, paciente Manoel Fortunato de Araújo Costa, j. 31.1 .1905 (em O Direito, Rio de Janeiro, vol. 98, p. 469). O caso ocorreu na vigência da Constituição de 1891, cujo art. $72, \S 11$ dispunha: "A casa é o asilo inviolável do indivíduo; ninguém pode aí penetrar, de noite, sem o consentimento do morador, senão para acudir a vitimas de crimes, ou desastres, nem de dia, senão nos casos e pela forma prescritos na lei".

O Decreto legislativo n. 1.151, de 5 de janeiro de 1904, que havia reorganizado os serviços de higiene administrativa da União, conferira ao governo competência para estabelecer "as medidas repressivas necessárias, a fim de tornar efetivas a notificação das moléstias infectuosas, a vigilância e a polícia sanitárias, e enfim todas as necessárias medidas executivas e disposições regulamentares" (art. $1^{2}, \S 1^{2}$ ). Com base nisso, por meio do Decreto n. 5.156, de 8 de março de 1904, o Executivo editara um regulamento dos serviços sanitários pelo qual se previu que: a) "a polícia sanitária será exercida pelos inspetores sanitários com superintendência dos delegados de saúde, em visitas sistemáticas a todas as habitações particulares ou coletivas, estabelecimentos de qualquer espécie..." (art. 84); b) "nos casos de oposição às visitas a que se referem os regulamentos da diretoria geral de saúde pública, o inspetor sanitário intimará o proprietário ou seu procurador, arrendatário, locatário, morador ou administrador a facilitar as visitas no prazo de 24 horas, recorrendo, quando a intimação não for cumprida, à respectiva autoridade policial a fim de ser realizada a visita, e impondo, ao mesmo tempo, a multa de $200 \$$ por desobediência à ordem legal" (art. 128); e c) "ordenada a desinfecção pela autoridade sanitária, ninguém poderá dela eximir-se, nem embaraçar ou impedir sua execução, sob pena de multa de $200 \$$ ou prisão por 8 dias a um més, devendo o inspetor sanitário requisitar auxílio da polícia para que a operação sanitária seja levada a efeito imediatamenten (art. 172).

O paciente, invocando a inviolabilidade domiciliar, foi ao STF contra a ordem de inspetor sanitário para franquear sua residência a fim de que se procedesse à desinfecção por motivo de febre amarela. Confiram-se os considerandos do acórdăo: "- Considerando, porém, que a entrada forçada em casa de cidadão para o serviço de desinfecção, sendo apenas autorizada por uma disposição regulamentar, importa flagrante violação do art. $72, \S 11$ da Constituição Federal, o qual cometeu à lei o encargo de prescrever em que casos é permitida de dia a entrada em casa particular sem consentimento do respectivo morador; - Considerando também que não colhe o argumento de que o Regulamento de que se trata foi expedido em virtude de autorização conferida pela Lei $n$. 1.511, de 5 de janeiro de 1904, a qual encarregou o Poder Executivo de organizar o respectivo serviço sanitário, visto como, restringida a questão à espécie vertente nos autos, sendo função exclusivamente legislativa regular a entrada forçada em casa de cidadão nos expressos termos do mencionado $\S 72$, não podia o Congresso nacional subdelegar essa atribuição ao Governo sem ofender a mesma Constituição Federal, que traçou a esfera do poder político; - Considerando, pois, sendo inconstitucional a disposição regulamentar que faculta à autoridade sanitária penetrar, até com o auxílio da força pública, em casa particular para levar a efeito operaçōes de expurgos, a coação que de tal ato possa provir é manifestamente injusta, e, portanto, a iminência dela importa ameaça de constrangimento ilegal que legitima a concessão do habeas corpus preventivo".

Apesar dessa peremptória tomada de partido da Corte Constitucional, Carlos Maximiliano, em suas anotaçōes ao dispositivo, sustentou, referindo-se ao ingresso de autoridade em domicilio: "Dá-se a entrada de dia quando autorizada por lei ou regulamento administrativo" (Comentários à Constituição Brasileira. 2" ed. Rio de Janeiro: Jacintho Ribeiro dos Santos Editor, 1923, p. 672).

(21) O precedente mais remoto é o acórdão de 16.5.1925 (Revista Forense 47/110), seguido dos acórdảos de 6.7.1948 (2" T., Rec. 13.377, rel. Lafayette de Andrada, em Direito 53/273), 20.12.1948 (1* T., rel. Ribeiro da Costa, em DJ de 9.8.50), 8.5.1951 (2^ T., RE 18.516-DF, rel. Lafayette de Andrada) e 12.1.1954 (2 T., Agravo de Instrumento 16.557-DF, rel. Orosimbo Nonato). 
rém, a $1^{2}$ Turma da Corte decidiu diferentemente, com base em voto do Min. Nelson Hungria, segundo quem a lei "não permite o abuso do direito, o exercício do direito pelo só e acintoso capricho de exercê-lo. É certo que ao morador assiste o direito de excluir do âmbito de seu domicílio pessoas estranhas, mas todo direito tem limites racionais, dentro dos próprios princípios gerais da ordem jurídica, e um desses limites é, precisamente, aquele que não permite que exerça um direito além de sua necessidade prática, por mero capricho ou emulação e em detrimento de outrem". ${ }^{(22)}$ Posteriormente, acolhendo embargos a esse acórdão, o Plenário, embora dividido, restabeleceu sua jurisprudência anterior. ${ }^{(23)}$

No regime constitucional de hoje, a primeira impressão, resultante da literalidade da norma, é que o ingresso forçado de autoridades sanitárias em ambiente privado só seria viável por determinação judicial. Sequer a lei poderia obrigar o indivíduo a suportar o ingresso sem tal determinação. Haveria, portanto, uma reserva de jurisdição a respeito. Será correta essa leitura?

As decisões do STF relativas a invasões, policiais ou não, com objetivos de investigação no interior do domicílio, têm sido no sentido da imprescindibilidade do mandado judicial. ${ }^{(24)}$ Ademais, em caso no qual o Es-

(22) 1 T., RE 27.866-DF, 4.4.1955. Votou vencido o Min. Ribeiro da Costa, amparado na jurisprudência anterior da Corte e declarando que "dentre as medidas concernentes aos direitos e garantia individuais, remanesce e perdura desde a Coonstituição do Império ... o princípio da inviolabilidade do domicílio, sujeito apenas às exceções da lei. Só a cláusula legal, pois, pode derrogar essa garantia, limitando-se aos casos expressamente prescritos, a fim de preservar o locatário na defesa do seu lar, resguardando a intimidade de sua família, o próprio pudor desta, e, assim, opondo-se à entrada de terceiros, desconhecidos". Em 24.1.957, a 1' T., no RE 31.137-DF, rel. Candido Mota Filho, confirmou o entendimento acolhido pela maioria no RE 27.866-DF.

(23) Tribunal Pleno, Embargos ao RE 27.866-DF, 27.8.1957, rel. Lafayette de Andrada (quatro votos vencidos). Ao que parece, a Corte não voltou depois ao assunto, pois a lei do inquilinato passou a prever expressamente o dever de o inquilino permitir a visita do imóvel. A lei atual, n. 8.245, de 18.10.1991, editada já na vigência da Carta de 1988, prevê, no art. 23, IX, entre os deveres do locatário o de "permitir a vistoria do imóvel pelo locador ou por seu mandatário, mediante combinação prévia de dia e hora, bem como admitir que seja o mesmo visitado e examinado por terceiros, na hipótese prevista no art. $27^{n}$ (isto é, de alienação do imóvel). Não consta a existência de impugnações a essa norma ao fundamento de que a Constituição vigente teria exigido ordem judicial como condição do constrangimento ao direito à inviolabilidade do domicílio, mas isso se explica porque o locador não tem meios para executar por si a pretensão de vistoriar ou visitar, de modo que a recusa do locatário conduzirá sempre à necessidade de intervenção judicial, apesar de não exigida expressamente pela lei.

(24) As seguintes referências da jurisprudência constitucional podem ser colhidas nas palavras de Alexandre de Moraes (Constituição do Brasil Interpretada. São Paulo: Atlas, 2002, pp. 236/238: a) “...nem a Polícia Judiciária, nem o Ministério Público, nem a administração tributária, nem quaisquer outros agentes públicos podem, a não ser afrontando direitos assegurados na Constituição da República, ingressar em domicilio alheio, sem ordem judicial ou sem o consentimento de seu titular ... com o objetivo de, no interior desse recinto, procederem a qualquer tipo de perícia ... ou de apreenderem, sempre durante o periodo diurno, quaisquer objetos que possam interessar ao Poder Público" (STF, RE 251.445-4/GO - rel. Min. Celso de Mello, despacho); b) “... nem a Polícia Judiciária, nem a administração tributária podem, afrontando direitos assegurados pela Constituição da República, invadir domicílio alheio com o objetivo de apreender, durante o período diurno, e sem ordem judi- 
tado pretendeu, sem mandado judicial, evacuar área pública indevidamente ocupada por barracos, o Presidente da Corte Constitucional a isso se opôs, entendendo que a medida feriria o direito à inviolabilidade domiciliar dos moradores. ${ }^{(25)}$ A tônica comum, nas hipóteses que geraram essa jurisprudência, está na individualidade das medidas e na ocorrência de algo maior do que a simples vulneração da intimidade do lar, pois em todas elas a invasão tinha como subproduto um efeito negativo para o particular: ou a produção de prova de infração penal ou administrativa, ou a perda da própria moradia.

O ingresso forçado no contexto de um programa de vigilância epidemiológica em que se busque a cobertura total (como no caso da dengue) é uma situação muito diferente. A medida é claramente geral, envolvendo todos os ambientes de uma dada região. Não há um endereço específico nem cunho de pessoalidade. Na decisão de vistoriar não se leva em conta qualquer característica individual do morador, o qual pode permanecer no anonimato; dele nada se subtrai, contra ele nada se produz. Daí a impertinência do mandado judicial.

A exigência de prévia autorização judicial para certas interferências estatais na vida privada não é formalidade vazia. Trata-se da atribuição, ao

cial, quaisquer objetos que possam interessar ao Poder Público. A Constituição Federal prescreve, no art. $145, \S 1^{2}$, que a administração tributária está sujeita, na efetivação das medidas e na adoção de providências que repute necessárias, ao respeito. incondicional aos direitos individuais, dentre os quais avulta, por sua indiscutivel importância, o direito à inviolabilidade domiciliar" (STF, Ação Penal 307-3/DF, DJU 13.10.1995, trecho do voto do Min. Celso de Mello); c) "... a essencialidade da ordem judicial para efeito de realização das medidas de busca e apreensão domiciliar nada mais representa, dentro do novo contexto normativo emergente da Carta Política de 1988, senão a plena concretização da garantia constitucional pertinente à inviolabilidade do domicilio. Daí a advertência - que cumpre ter presente - feita por Celso Ribeiro Bastos, no sentido de que 'é forçoso reconhecer que deixou de existir a possibilidade de invasão por decisão de autoridade administrativa, de natureza policial ou não. Perdeu portanto a Administração a possibilidade da auto-executoriedade administrativa"n (STF, Ação Penal 307-3/DF, DJU 13.10.1995, trecho do voto do Min. Celso de Mello).

(25) Despacho do Min. Celso de Mello - Presidente, na Suspensão de Segurança n. 1203, Distrito Federal x TJDF, j. 8.9.1997 (RDA vol. 210, p. 270), do qual se colhem estes trechos: "A Carta Federal, pois, em cláusula que tornou juridicamente mais intenso o coeficiente de tutela dessa particular esfera de liberdade individual, assegurou, em benefício de todos, a prerrogativa da inviolabilidade domiciliar. Sendo assim, ninguém, especialmente a autoridade pública, pode penetrar em casa alheia, exceto (a) nas hipóteses previstas no texto constitucional ou (b) com o consentimento de seu morador, que se qualifica, para efeito de ingresso de terceiros no recinto doméstico, como o único titular do respectivo direito de inclusão e exclusão. (...) Sendo assim, nem os organismos policiais e nem a Administração Pública, afrontando direitos assegurados pela Constituição da República, podem invadir domicilio alheio, sem a prévia e necessária existência de ordem judicial, ressalvada a ocorrência das demais exceções constitucionais" (...) O respeito (sempre necessário) à garantia da inviolabilidade domiciliar decorre da limitação constitucional que restringe, de maneira válida, as prerrogativas do Estado e, por isso mesmo, não tem o condão de comprometer a ordem pública, especialmente porque, no caso, como é enfatizado, as liminares em referência não impedem o Governo do Distrito Federal de exercer, com regularidade, o poder de polícia que lhe é inerente, circunstância esta que Ihe permite adotar as providências administrativas necessárias à evacuação da área, desde que observadas as concernentes prescrições constitucionais". 
Judiciário, do ônus de verificar a existência de fatos específicos e sérios capazes de legitimar a medida excepcional da intromissão. É uma precaução contra o abuso policial e administrativo, contra a ação sem causa individual legítima. Mas que sentido haveria no requerimento, formulado pela autoridade sanitária, de autorização judicial para ingresso forçado em todas as casas de uma cidade à cata de criadouros de mosquitos? Que exame fático caberia ao juiz?

\section{CONCLUSÃO}

Essas ponderações e perplexidades são suficientes para a conclusão de que 0 acesso compulsório aos ambientes privados pelos agentes da vigilância epidemiológica, incumbidos do programa de combate à dengue, não depende da autorização judicial a que se refere 0 art. $5^{\circ}, \mathrm{XI}$, da Constituição Federal. Caso, no entanto, por apego à literalidade da regra, se queira obter essa autorização - até por cautela, visto o rigor da sanção penal contra a violação de domicílio (Código Penal, art. 150) -, o requerimento poderá ser genérico, englobando a totalidade dos imóveis a vistoriar, já que a causa da medida é o combate universalizado a uma epidemia, não qualquer circunstância ligada a uma casa em particular. Não é preciso que a autoridade comprove previamente a resistência do morador, pois a causa do pedido não é a recusa, mas a necessidade de entrar.

A dúvida remanescente é quanto à suficiência ou não das leis existentes, seja para a ação administrativa direta, seja para a via mais conservadora, de pedido de autorização judicial genérica. Há em vigor, como visto, lei atribuindo às autoridades sanitárias competência para sujeitar as pessoas a medidas de controle das doenças, mas não há previsão legal específica quanto ao ingresso forçado nos domicílios. Terá essa ausência efeito proibitivo? Constatamos que o Supremo Tribunal Federal assim entendeu no passado, mas também é verdade que o fundamento dessa jurisprudência, que era a reserva legal expressa na norma constitucional sobre inviolabilidade domiciliar, desapareceu na Constituição de 1988. De modo que a questão passou a sujeitar-se à regra geral de legalidade do art. $5^{\circ}$, II, da Constituição, segundo o qual as constrições à liberdade são viáveis quando feitas "em virtude de lei”, não precisando ser necessariamente feitas pela própria lei. A legislação atual é, portanto, suficiente.

Uma última questão é pertinente. O que sucederá se um morador resistir, impedindo o ingresso dos agentes sanitários em sua casa? A hipótese se subsume à Lei n. $6.437 / 77$, que prevê as sanções de "advertência e/ou multa" para quem "impedir ou dificultar a aplicação de medidas sanitárias relativas às doenças transmissíveis" (art. 10, VII). Mas essas penalidades, 
se têm muitas vezes efeito dissuasório, não resolvem o problema da resistência continuada. Qual a solução?

Pela mesma Lei, a imposição das sanções principia pela lavratura de um auto de infração (art. 12), com notificação do envolvido (art. 17). Se "subsistir, ainda, para o infrator, obrigação a cumprir" (como a de dar acesso ao domicílio), "será expedido edital fixando o prazo de 30 dias para o seu cumprimento" (art. 18, caput), podendo esse prazo "ser reduzido ou aumentado, em casos excepcionais, por motivos de interesse público, mediante despacho fundamentado" (art. 18, parágrafo único). O edital "será publicado uma única vez, na imprensa oficial, considerando-se efetivada a notificação 5 dias após a publicação" (art. 17, § $2^{\circ}$ ).

E se, passado o prazo concedido no edital, insistir o morador em sua recusa obstinada? Aí sim poderá ocorrer a "execução forçada", ou, se a Administração o preferir, "a imposição de multa diária, arbitrada de acordo com os valores correspondentes à classificação da infração, até o exato cumprimento da obrigação, sem prejuízo de outras penalidades previstas na legislação vigente" (art. 19).

É inevitável a constatação quanto a pouca utilidade dessa execução forçada, no contexto de um programa de combate à dengue envolvendo milhares de imóveis, em toda uma região ou cidade. O procedimento é, reconheça-se, longo, oneroso e, por isso, caro. Dificilmente se poderá ver na execução forçada o instrumento para tornar efetiva a cobertura total; será, quando muito, mecanismo pedagógico, a empregar seletivamente, para efeito publicitário. Só que talvez o nó não esteja na complexidade desse procedimento, que de resto pode ser abreviado por lei, mas na impropriedade da violência como instrumento de universalização de programas públicos.

Aí o desafio da eficácia terá de ser vencido mesmo com as velhas estratégias da ameaça de sanção - e a multa, sanção econômica, é nesse caso muito mais capaz de intimidar - e da campanha pelo engajamento cívico. 